\title{
A Rural Transit Vehicle Management System and Condition Predictor Model
}

\author{
Michael D. Anderson and Adam B. Sandlin \\ The University of Alabama in Huntsville
}

$\overline{\text { Abstract }}$

In an ongoing effort to improve mobility and quality of life for Alabama's citizens, a computer database system has been developed to improve the State's ability to manage and assess the condition of its rural transit fleet. The development of this management program consisted of a physical inspection of all state-owned vehicles. Upon completion of the physical inventory, the research team developed a vehicle inventory database to track Alabama's public transit vehicles and a data model to predict the condition of individual vehicles. The prediction model is presented as a tool to allow the State Department of Transportation to assign an individual vehicle condition rating for each vehicle, without the cost of a physical inventory. This vehicle rating is intended to support the equitable acquisition and disposal of vehicles reflecting the varied roadway conditions and socioeconomic conditions found statewide.

\section{Introduction}

Personal mobility is a vital component of an individual's welfare and quality of life. However, in many rural areas of Alabama, a large portion of the residents lack the resources or ability to provide for their own mobility and are dependent on the State's rural transit program. Alabama's rural public transit system (49 U.S.C. Section 5311) consists of 27 individual operators located 
throughout the State, with each operator responsible for a geographical area in the state ranging in size from one to nine counties (University Transportation Center for Alabama 2000). The vehicles comprising this fleet are generally 15passenger standard vans or cutaway chassis vehicles seating between 17 and 21 passengers. The rural transportation program in Alabama provides residents with needed transportation services for shopping, medical, social/recreational, and other trip purposes.

To maintain the rural public transit fleet in the best operating condition, a fleet management system has been developed to improve the State's ability to assess the condition of its rural transit fleet and better justify vehicle acquisition strategies. The program consists of a physical inspection of all state-owned vehicles to verify vehicle identification numbers and collect current mileage, age, and overall condition of the vehicle based on physical appearance, perceived passenger comfort level, and maintenance needs. The data collected will be used to develop a vehicle inventory database to track Alabama's public transit vehicles, and design a data model to predict the condition of individual vehicles based on vehicle age, mileage, roadway conditions, and general countywide or regionwide statistics. The prediction model will be presented as a method to assess vehicle condition, without the cost of a physical inventory, to support the equitable acquisition and disposal of vehicles reflecting the varied roadway conditions found statewide.

This article explores how the statewide vehicle inventory database was developed, and the design of the vehicle condition predictor model. It presents the results of the physical inventory, the database development to manage the existing and expanded fleet, and the predictor model developed to assess a condition rating for rural public transit vehicles to be used for vehicle acquisition and disposal decisions in future years. The article concludes with some analysis of the variables used in the predictor models such as the influence of regional income levels and the impact of nonpaved roadways on vehicle condition.

\section{Data Collection Effort}

The data collection effort involved an on-site inventory of all rural public transit vehicles in Alabama. An inventory form was developed to assist in the data 
collection process. The form was used by the examiners as they walked around the vehicles from the front driver's side to the rear (Figure 1). Items collected on the form include vehicle identification number, mileage, seating capacity, and vehicle type. In addition to these basic data elements, each inspector was required to assign a condition rating to the vehicle based on its physical appearance, perceived passenger comfort level, and maintenance needs. Possible condition ratings were excellent, good, fair, poor, and bad, with each being assigned a number from four to zero, respectively. The condition ratings assigned to the vehicles were intended to define the urgency of each vehicle with respect to replacement. For example, a vehicle given a "bad" rating should be replaced immediately as it is no longer considered safe and comfortable for passenger transit. A vehicle with a "poor" rating is one that might need to be replaced, however, it is not an urgent matter. See Anderson (2000) for a complete review of col-

\begin{tabular}{|c|c|c|c|}
\hline $\begin{array}{l}\text { Regislered Owner } \\
\text { Mame }\end{array}$ & Baldwin County & & \\
\hline Vin Number & 1FDKE30G2NHB65013 & Verificalion 1999 & ai \\
\hline $\begin{array}{l}\text { Chassis } \\
\text { Manufacturer }\end{array}$ & Ford & Design Capacity & 17 \\
\hline Mileage & 219360 & Vehicle Type & CV \\
\hline $\begin{array}{l}\text { Body } \\
\text { Manufacturer }\end{array}$ & Supreme & Model Year & 1993 \\
\hline $\begin{array}{l}\text { Body Serial } \\
\text { Number }\end{array}$ & NO 8454 BS 25 & Federal Program & 5311 \\
\hline Tag Number & $19120 \mathrm{CO}$ & Dellvery Date & $10 / 2 / 92$ \\
\hline Lift_Equipped & 9 & & \\
\hline Lift Manufacturer & Braun & $\begin{array}{l}\text { Year } \\
\text { Yearement }\end{array}$ & \\
\hline Stations & 2 & Total Cost & $\$ 40,614.00$ \\
\hline Comments: & UAH condition raling $=$ poor & & \\
\hline
\end{tabular}

Figure 1. Inventory collection form 
lected data. To ensure consistency in the condition rating between different data collectors, all people associated with the vehicle inventory calibrated their condition rating using a single agency, with the Alabama Department of Transportation present. This calibration exercise, which included discussion of features and conditions, was used to ensure that all data collectors were assigning consistent ratings. The data collection effort required approximately 600 hours of work and was performed for a period of three months.

\section{Database Development}

The database was designed to allow for new vehicle acquisition, annual updates, and vehicle disposals. Using Microsoft's Access Database program (Microsoft Corporation), a table was developed containing all required fields to support these three stages in a vehicle's life. Then, separate data entry and report forms were developed to review, alter, or enter specific vehicle information. (See Figures 2 and 3 for examples of the forms for vehicle acquisition and disposal.)

\section{Vehicle Predictor Model}

In addition to the vehicle database, a vehicle condition rating predictor model was developed to identify vehicles in need of replacement in future years without the costly physical inventory. Initially, it was assumed that the vehicle condition rating would be a function in the form

Vehicle Condition Rating $=f($ age, mileage $)$.



Figure 2. Vehicle acquisition form 


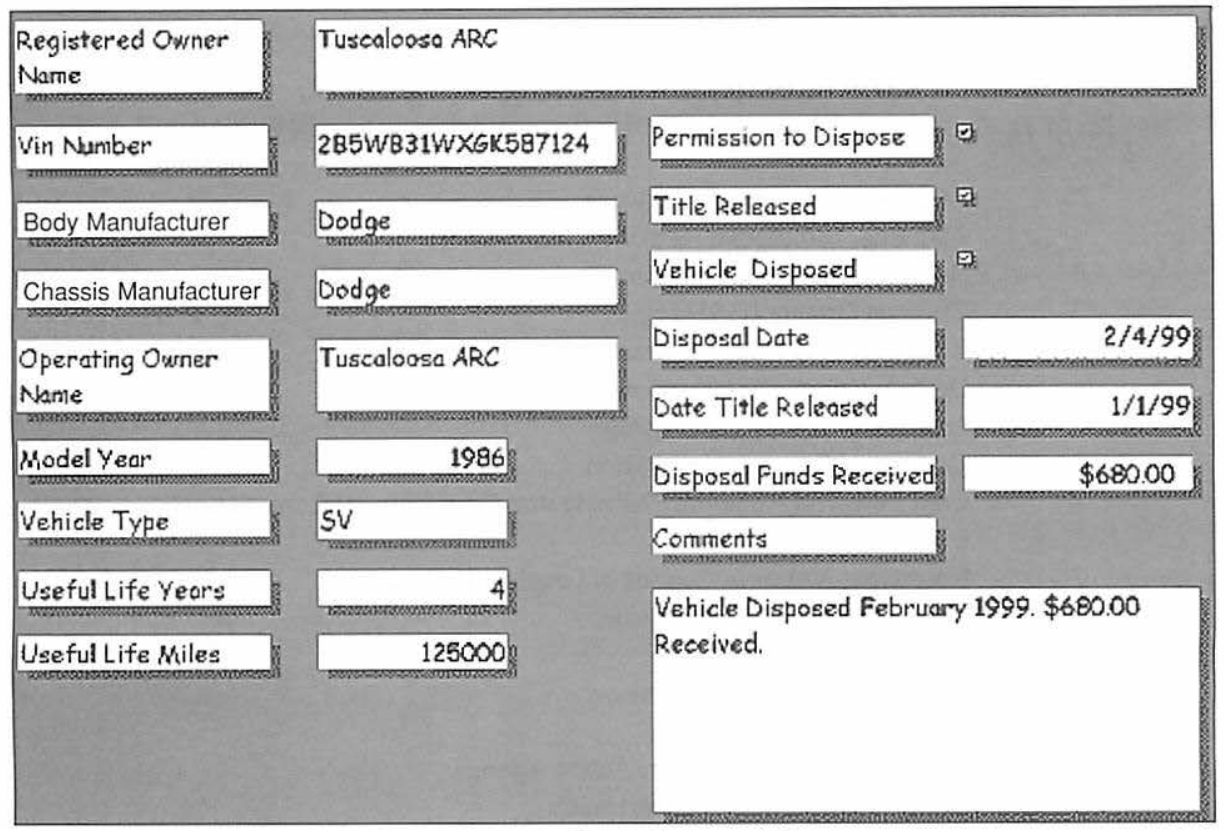

Figure 3. Vehicle disposal form

However, when the database records were entered into a regression analysis using these two variables, the prediction equation for the vehicles was:

Vehicle Condition Rating $=3.975-0.243$ (age) -0.00000445 (mileage)

The best adjusted correlation coefficient (adjusted $R$ squared) for the data was only .52. The model was predicting just over half of the variables necessary to determine the condition rating. However, using this equation and a sample rural transit vehicle driven 20,000 miles per year, the decrease in vehicle condition rating would drop to approximately zero after 12 years of operation.

Applying Equation (2) to determine vehicle acquisitions, Table 1 shows a comparison of the anticipated number of vehicles each agency would receive (70 total vehicles as would be purchased in a typical year) using the physical inventory results and Equation (2). The number of vehicles each agency would receive using the physical inventory was developed by ordering the vehicles with respect to age and mileage, then selecting the 70 oldest vehicles with highest mileage used to break ties between vehicle age. Using Equation (2), the 70 vehicles with 


\begin{tabular}{|c|c|}
\hline \multicolumn{2}{|c|}{$\begin{array}{c}\text { Table } 1 \\
\text { Vehicle Acquisitions Using Equation (2) }\end{array}$} \\
\hline \multicolumn{2}{|c|}{ Physical Inventory } \\
\hline 25 & West Alabama Health Services \\
\hline 7 & Alabama Tombigbee Regional Commission \\
\hline 6 & Baldwin County Commission \\
\hline 5 & Cullman County (CARTS) \\
\hline 4 & Blount County Public Transportation \\
\hline 4 & DeKalb County Commission \\
\hline 3 & Lawrence County Commission \\
\hline 2 & Covington County Commission \\
\hline 2 & East Alabama Regional Planning and Development Commission \\
\hline 2 & Exceptional Children \\
\hline 2 & Northwest Alabama Council of Local Governments \\
\hline 1 & Cleburne County Commission \\
\hline 1 & Decatur, City of \\
\hline 1 & Escambia County Commission \\
\hline 1 & H.E.L.P. Inc. \\
\hline 1 & Macon Russell Community Action Agency \\
\hline 1 & Northwest Alabama Mental Health \\
\hline 1 & Shelby County Commission \\
\hline 1 & Southeast Alabama Regional Planning \& Development Commission \\
\hline 70 & Total vehicles \\
\hline \multicolumn{2}{|c|}{ Equation (2) } \\
\hline 34 & West Alabama Health Services \\
\hline 6 & Alabama Tombigbee Regional Commission \\
\hline 5 & Northwest Alabama Council of Local Governments \\
\hline 4 & Blount County Public Transportation \\
\hline 3 & Baldwin County Commission \\
\hline 3 & Exceptional Children \\
\hline 2 & H.E.L.P. Inc. \\
\hline 2 & Lawrence County Commission \\
\hline 2 & Northwest Alabama Mental Health \\
\hline 2 & Southeast Alabama Regional Planning \& Development Commission \\
\hline 1 & Covington County Commission \\
\hline 1 & Cullman County (CARTS) \\
\hline 1 & DeKalb County Commission \\
\hline 1 & Escambia County Commission \\
\hline 1 & Jackson County Commission \\
\hline 1 & Macon Russell Community Action Agency \\
\hline 1 & Morgan County Commission \\
\hline 70 & Total vehicles \\
\hline
\end{tabular}


the lowest vehicle condition rating were selected. Examining Table 1 shows that the simple vehicle condition rating predictor model seems to identify the same general list of agencies that are in need of replacement vehicles as the physical inventory. However, the number of vehicles that each agency would be entitled to purchase under this model showed some wide variation.

For the 70 vehicles that would be acquired following the calculated rating in Table 1, all had a calculated vehicle condition rating less than 1.34. If the State wanted to remove all vehicles in less than "fair" condition, it would need to replace 216 vehicles (out of 483 vehicles, or $45 \%$ ), as the average calculated vehicle rating was 2.06. (For comparison, the physical inventory average rating was 2.02.) Reviewing the results of the simple model formulation, the model to predict vehicle condition rating presented in Equation (2) provides a reasonable method to predict vehicle condition as the average condition rating and acquisitions per agency were similar. However, with the high degree of uncertainty in the model and the differences in vehicle acquisitions, it might be difficult to convince representatives from all agencies that this model produced the most equitable distribution.

To improve the prediction equation, it was recalled that while conducting the physical inventory some relatively new vehicles were determined to be in "poor" or "bad" condition due to external factors, such as engine troubles or faulty air conditioners. It was hypothesized that these vehicles were having a negative influence on the predictor model, essentially introducing uncertainty in the model as these vehicles did not follow the typical vehicle pattern and would therefore be considered problem vehicles that would be replaced independently from the population of typical vehicles. Therefore, the physical inventory records were reviewed and 24 vehicles that received low condition ratings based on maintenance or other mechanical problems were removed from the sample. After this operation was performed, a new predictor model based on mileage and age was developed (although miles per year was used instead of total mileage):

Vehicle Condition Rating $=4.07-0.258$ (age) -0.000026 (mile/yr) 
The best adjusted correlation coefficient (adjusted $R$ squared) for the data improved to .62. Although this new equation improved the adjusted $R$-squared value, application of this equation predicted the highest calculated vehicle rating for the 70-vehicle replacement scenario being 1.27 ; the average calculated rating continued to be 2.06, while the physical inventory increased to equal 2.06 .

To further improve the vehicle predictor model, other factors beyond age and mileage that might possibly affect the rural public transit fleet condition were introduced into the equation. Additional factors included varying roadway conditions encountered while traveling in the State (essentially the percentage of unpaved roadway in the county or region multiplied by vehicle miles of travel) and socioeconomic measures for the county or region. Table 2 shows all the variables that were added to the vehicle predictor model.

When entering these values into MINITAB (a commercial statistics software), it was determined that seven of the variables were insignificant in the prediction of condition (MINITAB, Inc.). This left a nine-variable prediction equation for determining vehicle condition rating, presented as

Vehicle Condition Rating $=2.01-0.255$ (Age) -0.000070 (mile/yr on unpaved roadways) -0.155 (lift equipped) -0.000002 (population) +20.4 (\% 1-person households) -1.51 (\% who work inside the county $)+96.8$ (\% transit commuters $)-7.60$ (\% poverty) -0.0253 (household density).

The best adjusted correlation coefficient (adjusted $R$ squared) for the data improved to .67. Again, the calculated average vehicle condition rating for the fleet was 2.06, which equaled the physical inventory average for the fleet. In addition, this model was tested for linearity (through a plot of the residual values) and distribution of variables (through a plot of residual values versus variables in the model), as prescribed in a common statistical text (Montgomery and Peck 1992). Table 3 shows vehicle distribution using the physical inventory and Equation (4). 


\begin{tabular}{|l|}
\hline \multicolumn{1}{c|}{ Table 2} \\
Variables Added to Improve Predictor Equation \\
\hline Age of the vehicle \\
Miles per year driven on paved roadways \\
Miles per year driven on unpaved roadways \\
Land accessible via unpaved roadways \\
Does the vehicle have a wheelchair lift? \\
Population of county or region \\
Percent of population making less than $\$ 15,000$ \\
Percent of population older than 65 \\
Percent of population younger than 18 \\
Percent of one-person households \\
Percent minority \\
Percent working inside the county \\
Percent working outside the county \\
Percent commuters on public transit \\
Percent in poverty \\
Households per square kilometer \\
\hline
\end{tabular}

\section{Agency-Wide Vehicle Model}

After the data collection process was completed, it was decided to determine if there were any socioeconomic factors affecting the average vehicle condition rating for an entire agency. To perform this test, condition rating, age, and mileage were averaged to determine the agency statistics. The socioeconomic data used to determine the individual condition rating were added to the agency averages to determine the expected vehicle condition for each agency. Again, using MINITAB, the best equation for average condition rating is

Avg. Vehicle Rating $=0.58-0.239$ (avg. age) -0.000033 (avg. mile/yr paved) - 0.000055 (avg. mile/year unpaved) - 3.73 (\% income $<\$ 15,000)-0.000003$ (population) $+1.79(\%$ pop older than 65$)-$ $1.02(\%$ pop under 18$)+21.0(\%$ 1-person households $)-2.48(\%$ minority) +1.21 (\% work outside county) +150 (\% commuters public transit) 


\begin{tabular}{|lcc|}
\hline \multicolumn{1}{|c|}{ Table 3} \\
Vehicle Acquisitions & \\
\hline & & \\
\hline West Alabama Health Services & Equation (4) & $\begin{array}{c}\text { Physical } \\
\text { inventory }\end{array}$ \\
Alabama Tombigbee Regional Commission & 32 & 31 \\
Northwest Alabama Council of Local Governments & 7 & 7 \\
Baldwin County Commission & 6 & 5 \\
Cullman County (CARTS) & 3 & 4 \\
Blount County Public Transportation & 3 & 4 \\
Covington County Commission & 3 & 3 \\
Exceptional Children & 3 & 3 \\
DeKalb County Commission & 2 & 3 \\
Escambia County Commission & 2 & 2 \\
Lawrence County Commission & 2 & 2 \\
Jackson County Commission & 2 & 2 \\
Northwest Alabama Mental Health & 2 & 1 \\
Morgan County Commission & 1 & 1 \\
H.E.L.P.Inc. & 1 & 1 \\
\hline Total vehicles & 1 & 1 \\
\hline
\end{tabular}

The best adjusted correlation coefficient (adjusted $R$ squared) for the data was .67 .

\section{Results}

For Equation (4), the vehicle acquisition pattern statewide very closely follows the physical inventory conducted (Figure 4).

An examination of individual variables that contribute to the condition rating shows, as would be expected, the older the vehicle the lower the condition rating. One interesting aspect of the equation is that amount of travel on paved roads had no significant impact on vehicle condition; however, the amount of travel on unpaved roadways had a significant impact with the decrease in vehicle condition rating. In fact, the likelihood that a vehicle would experience unpaved roadway travel had a large influence on the vehicle condition rating, and no agencies with less than 24 percent unpaved roadways (with the exception of the Jackson County Commission's one vehicle) would be entitled to acquire any vehicles.

A vehicle-specific factor that tended to lower the condition rating was whether the vehicle had a wheelchair lift. The authors believe that these vehicles 


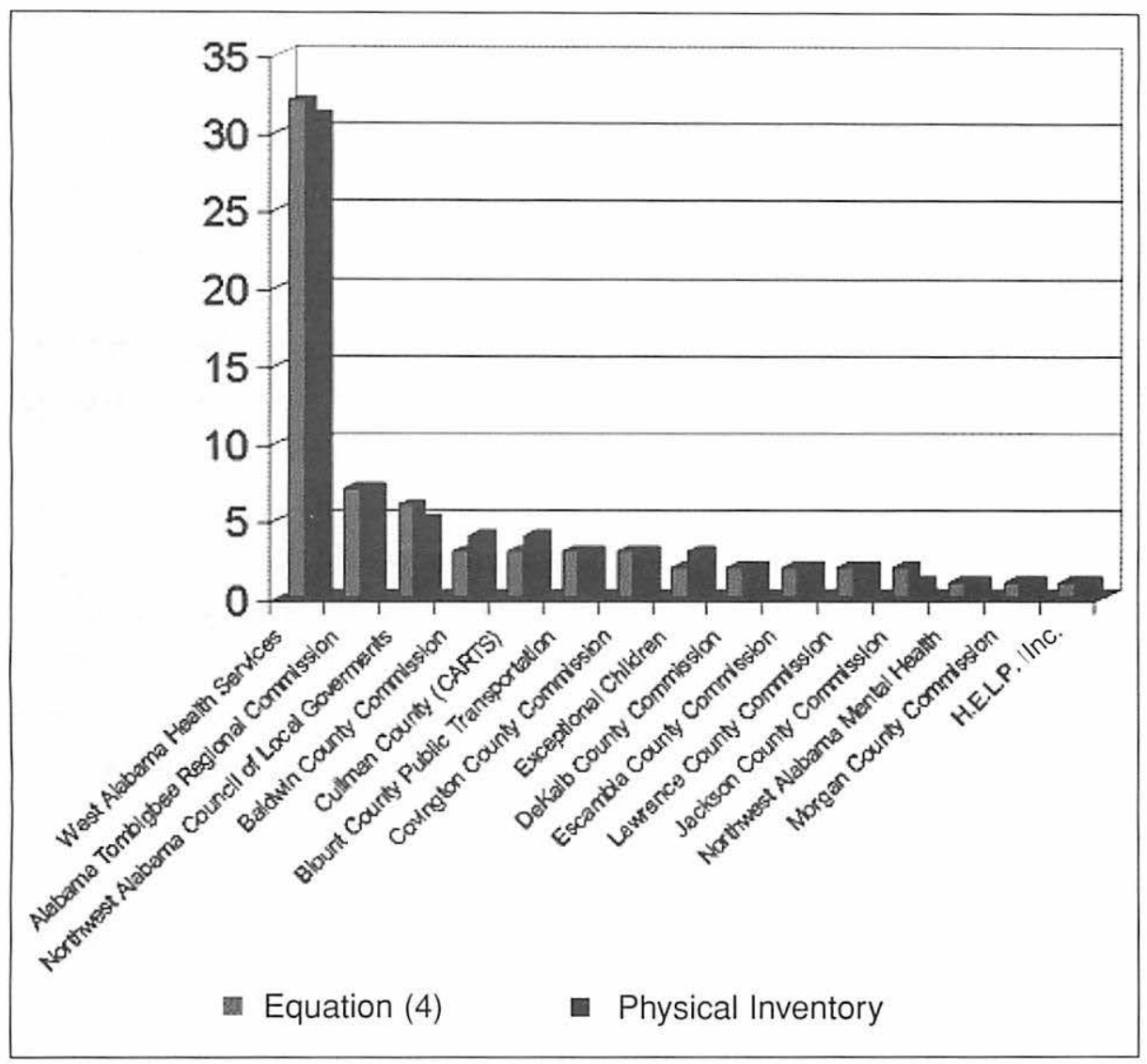

Figure 4. Vehicle acquisitions using Equation (4) and physical inventory

received a lower score based on the wear and tear and extra maintenance requirements for wheelchair-lift vehicles. Statewide there are 119 wheelchair-lift vehicles, and the 70-vehicle acquisition scenario identified 14 of these vehicles.

Countywide or regionwide socioeconomic factors including population, percentage of the population living in poverty, and percentage of individuals working inside the county all generally reduce the vehicle condition rating; whereas having a large percentage of one-person households tended to increase the vehicle condition rating. Interestingly, agencies reporting a high amount of commuters who use public transit actually had improved vehicle condition ratings. The authors believe agencies with an increased percentage of riders are required to keep vehicles in better condition to retain the high usage. 
In examining the average vehicle condition ratings for an agency and vehicle and socioeconomic factors, the data showed that increases in age, mileage on paved roads, and mileage on unpaved roads all decreased vehicle ratings. When comparing paved to unpaved roadways, the average travel on unpaved roadway mileage accounted for more than 62 percent of the vehicle condition rating reduction experienced for total travel. Increases in population, percentage of low-income residents, percentage of young residents, and percentage of minorities in a county or region all reduced the agency's average vehicle condition rating. The authors believe these socioeconomic factors, especially low-income residents and young residents, limit an agency's ability to generate matching funds required to acquire new vehicles even if an equitable distribution of vehicle acquisition would allow the agency to purchase more vehicles. Socioeconomic factors that allow an agency to increase average vehicle condition ratings are percentage of one-person households, percentage of residents who work outside the county, and percentage of commuters.

\section{Conclusions}

The State of Alabama's commitment to improve the mobility and quality of life for its citizens was the driving force behind the physical inventory. Developing an inventory system and vehicle condition prediction model to identify vehicles that should be replaced will help ensure that an agency's need for new rural public transit vehicles is identified. This improved ability to identify vehicles in need of replacement through the agency's submission of annual mileage and vehicle age reports (which are currently required) will enable the Department of Transportation to establish a vehicle acquisition schedule without the costly physical inventory. Overall, application of the vehicle condition predictor model will allow the state to allocate new vehicle purchases in an equitable pattern to ensure all residents are traveling in the best possible vehicles.

\section{Acknowledgments}

The authors would like to thank the Alabama Department of Transportation Multimodal Transportation Bureau for funding this study, and all 5,311 agencies in Alabama for cooperating with the individuals conducting the vehicle inventory. 


\section{References}

Anderson, M. D. May 2000. Vehicle inventory of Alabama's 5,311 rural transit fleet. Developed for the Alabama Department of Transportation Bureau of Multimodal Transportation, Montgomery, AL.

Microsoft Corporation. Microsoft Access 97. Redmond, WA.

MINITAB Inc. MINITAB statistical software, Release 13.20. State College, PA.

Montgomery, D. C. and Peck, E. A. 1992. Introduction to linear analysis 2 nd ed. New York: Wiley Publishing.

University Transportation Center for Alabama (UTCA). August 2000. Alabama public transportation needs assessment. Tuscaloosa, AL: University of Alabama.

\section{About the Authors}

MiChaEl D. ANDERSON (mikea@cee.uah.edu), an assistant professor of civil engineering at the University of Alabama in Huntsville, is working on rural public transportation and transportation forecasting. Dr. Anderson teaches courses in traffic engineering, urban planning, and Geographic Information Systems. He received his Ph.D. from Iowa State University in 1998.

ADAM B. SANDLIN (adamsan@hiwaay.net) is a graduate student studying civil engineering at the University of Alabama in Huntsville. Mr. Sandlin is a graduate of the university with a degree in engineering from the Department of Civil and Environmental Engineering. 